\title{
Factors Affecting Woman's Continuance Intention for Mobile Games
}

\author{
Pinghao Ye, Wuhan Business University, China \\ iD https://orcid.org/0000-0002-0822-7950 \\ Liqiong Liu, Wuhan Business University, China \\ Linxia Gao, Wuhan Business University, China \\ Quanjun Mei, Wuhan Business University, China
}

\begin{abstract}
The article finds the main factors affecting women's continuance intention for mobile games, and analyze how and to what extent these factors affect women's continuance intention for mobile games in a research model. In this study, a Model of Factors Affecting Women's continued interest in mobile gaming is comprised of eight variables and relevant hypotheses has been created based on a technology acceptance model (TAM), and three theories of flow theory, the theory of scenarios, and customer satisfaction theory. Also, a questionnaire survey involving 319 female mobile gamers was conducted, and all hypotheses have been verified using a structural equation model. Research results show that the perceived challenges, novelty, and cost of mobile games had significant positive effects on the perceived enjoyment of female mobile gamers; the mobility of mobile games had significant positive effects on the perceived ease-of-use of female mobile gamers; perceived enjoyment and ease-of-use had significant positive effects on female gamers' continuance intention for mobile games; while the security of mobile games had no significant effect on the perceived ease-of-use of female mobile gamers.
\end{abstract}

\section{KEYWORDS}

Continue to Use, Influence Factors, Mobile Game, Women

\section{INTRODUCTION}

Thanks to the rapid popularization of smartphones which provides us much easier access to internet technologies and interactive design, the burgeoning mobile games industry has experienced explosive growth in consumers, who, showing gradual acceptance of mobile games and gaming services, have turned from passive consumers to active consumers (Merikivi, Tuunainen, \& Nguyen, 2017). According to I-research, in 2016, China created a 102.28 billion yuan mobile games market with 521 million consumers, up $81.9 \%$ and $14.5 \%$ respectively over the previous year (Iresearch, 2017). A surprising fact is that today, most mobile gamers are female not male as thought by many. Mobile analytics company Flurry recently released a report, claiming that based on a sample of games that 
reached a total of 1.1 million devices on its platform, they have found that women make $31 \%$ more in-app-purchases than men, spend 35\% more time in gaming apps than men, and have $42 \%$ higher 7 -day retention on average versus males. The constantly growing number of female gamers has increased their position and importance, and of course, their value in the eyes of game developers. A consumer segmentation now, existing and potential female gamers have become an important force driving the development of the mobile games industry (Wang, Lee, \& Hsu, 2017). Women tend to spend more money on in-app-purchases. Compared to men, they also spend more time in gaming and social apps during break and travel times, and before sleep, obtaining aesthetic experiences in this process. Even though, factors affecting women's continuance intention for mobile games have seldom been studied at present.

In previous studies, models and theories for using mobile games were mostly based on a specific model, and less introduction was provided to other theories; thus, a more comprehensive analysis of influencing factors was lacking. Moreover, limited research was conducted on the continuous usage intention of females. Hence, focusing on the continuous usage intention of female mobile game users and combining the scenarios and satisfaction theories, this study comprehensively investigates the influencing factors of the effective and continuous usage intention of female mobile game users, determines manners to engage users and increase user loyalty, thereby attracting and retaining more users and promoting the development of the mobile game industry.

In this study on the mobile games usage intension, the factors affecting the mobile games usage intention are summarized into three major factors-personal, technical, and social. Besides, based on the consumer acceptance theory, studies have also summarized the key factors for the success of mobile games-content innovation, game time, social network experience, and convenience of operation. Mobile games are associated with flow, and girls reported higher flow experience scores than boys $(\mathrm{d}=0.30)$ (Bressler, 2019).

A summary of previous reports concluded that in the measurement indicators covered by the technology acceptance theory, perceived entertainment and perceived usefulness are two determinants of the mobile games usage intension. Perceived efficiency and perceived interest exert a direct and positive impact on the adoption of mobile games. In addition, perceived entertainment plays a key role in the attitude of users, and age is a key factor in the adoption of mobile games. Furthermore, studies have suggested that performance expectation, expectation effort, social impact, and promotion conditions affect usage intension of users by determining the attitude of users to play games on mobile phones.

As the development of mobile games is yet to be improved in technical ability, scholars' research on mobile games tend to focus on the technical level; while the related research on user behavior is less, especially on the behavior of female users. In the available research, the following problems remain to be effectively resolved: how to effectively acquire more new female users? What factors affect the continuous usage intention of female users? How does the experience quality of female users of mobile games affect user stickiness?

The traditional theoretical model has a certain explanatory power for the related applications in the mobile Internet field, but the self-particularity of the mobile game declines the interpretation ability of a single model. Thus, it is essential to establish a specific model to enhance the predictive ability of the receptive behavior of mobile game users by combining relevant theories for specific applications. Thus, this study constructed an influence factor model of female continuous usage of mobile games based on the available research models and the characteristics of mobile games.

This study integrated flow theory and technology acceptance model to identity factors that influenced Women's intention to use mobile game. The rest of this paper is structured as follows.

Section 1 introduces the research background, research status and research problems. Section 2 shows the technical background of mobile games and the research status of user behavior. Section 3 discusses the research model and hypothesis. Section 4 presents the research methodology. Section 5 introduces the data analysis and results. Section 6 puts forward the conclusions. Section 7 Discussion 
the theoretical and managerial implications of the study. Section 8 Provides limitations and directions for future research.

\section{LITERATURE REVIEW}

Previous academic studies primarily focused on the design and development of mobile games, ignoring customer loyalty which has actually become a key factor affecting the market share of mobile games. During the study, we've noticed the lack of research on such factors as consumers' intention to play mobile games, consumer behavior in playing mobile games, and channels through which consumers introduce mobile games to other. Although there is little literature directly connected with our research, we've found a lot of indirectly connected literature studying SNS games and other mobile games for the elderly, students and the disabled.

\section{Profile of Mobile Game Development}

Such studies mainly focus on the status quo, history, development strategies and reshaping of the mobile games industry. Okazaki, Radoslav, and IIdefonso (2015) summarized the development of mobile games industry in Japan, Korea and the U.S., and analyzed factors affecting young people's choosing mobile games from a cross-cultural perspective. They divided online games into web games, network games and pure online games. Web games are online multi-player interactive games played through a web browser, requiring no downloading of apps, or high-performance computing configurations. Network games are network-based sustainable individual multiplayer online games, which, using operators' servers and gamers' computers as terminals, and apps for information interaction, provide entertainment, leisure, communication, and virtual experiences to players (Alzahrani, Mahmud, Ramayah, Alfarraj, \& Alalwan, 2017). Pure online games, with the largest number of players, comprise diverse genres, such as role-playing games, gladiatorial games, shooting games, puzzle games, and strategy games. Gamers may play different roles with the help of VR technology. Different roles, things and events, and surprising experiences are designed to help gamers gain a sense of achievement (Lee, Hsu, \& Chang, 2013; Lin, Hung, Fang, \& Tu, 2015; Lu \& Wang, 2008; Pan \& Fu, 2013).

Chang, Liu, and Chen (2014) conducted a questionnaire survey and built a structural equation model to verify the effects of hedonism and social factors on player continuance intention for mobile games. Results show that utilitarian motivations (good reputation, position, and effective value) can enhance the intention of gamers to constantly play games, and interactivity and multimedia enjoyment have become key factors determining game design. The study suggests that all factors of long-lasting enjoyment were equally important.

J. Hamari and Sjoblom (2017) studied factors affecting the appeal of eSport games. A pilot survey was conducted before a questionnaire survey involving 888 respondents. Results show that knowledge acquisition, escapism, and innovation had positive effects on gamers' frequency of playing online games. In the same year, (Vashisht \& Sreejesh) verified the effects of nature of advergame and moderating roles of game-product congruence and need for cognition on gamers' ad-persuasion from the perspectives of attention and elaboration. The results indicate that slow-paced advergames are more persuasive than fast-paced advergames.

The mobile games industry has shifted its focus from traffic acquisition and rapid realization to content innovation, industrial innovation and customer value maximization, including digging into the core value of female mobile gamers to develop their loyalty.

\section{Research on Mobile Game Implementation Technology}

Such studies mainly focus on the selection and design of mobile game development platforms. Thanks to advances in technology, mobile games have experienced the transition from black and white screens to color screens, and from 2D to 3D. At present, the most widely used mobile game engines are $\operatorname{Cocos} 2 \mathrm{~d}-\mathrm{X}$ for $2 \mathrm{D}$ games and Unity $3 \mathrm{D}$ for $3 \mathrm{D}$ games. The former, supporting cross-platform 
compiling, features a low technological threshold and a much shorter development cycle. Based on advanced game development models, Cocos $2 \mathrm{~d}-\mathrm{X}$ describes all objects in game development through integrated application of third-party databases, SDK components, and other resources and tools, avoiding chaotic processes (Ahreum, Kibrum, Hokyoung, Jieun, \& Gyuhyun, 2015; Chuang-Chun \& I-Cheng, 2016) during game development. Given the characteristics of Cocos2d-X, many researchers have studied the R\&D of Cocos2d-X-based mobile games (Yang Liu, Daniel, \& Dongping, 2016). Compared with Cocos2d-X, Unity3D, which also supports cross-platform compiling, additionally incorporates other functions such as DirectX and OpenGL graphics Libraries, and various components and scripts. Besides, game developers may purchase Unity3D development codes and models from Unity (Yang \& Sik, 2014). Boasting enormous advantages in the development of 3D games, Unity3D has been widely studied by foreign researchers for game design and development (Bae \& Kim, 2014). De Kervenoael, Palmer, and Hallsworth (2013) analyzed factors affecting consumer choice from industrial and technological perspectives, and found that consumer choice was affected by regulating the self-regulated, understanding anti-choice, boundary-setting and including the self-excluded.

User experience, especially product availability, has been widely studied. In comparison, there are only a few studies analyzing the affective reception and aesthetic experiences of gamers from very limited perspectives. In a word, current studies have only noticed the importance of customers' acceptance of games, but ignored the importance of customer loyalty.

\section{Empirical Research on Mobile Game User Behavior}

Previous studies on the behavior of mobile gamers mainly focus on factors affecting the willingness of gamers to play games, and some methods to increase the loyalty of gamers have been developed in the process of research (Park, Baek, \& Ohm, 2014). Most studies first built research models based on the TAM (Okazaki et al., 2015) and collected information, trying to find new factors affecting the behavior of gamers. Then, empirical studies were conducted to verify the research models. Okazaki et al. (2015) discovered that perceived ease-of-use directly affected perceived efficiency and perceived enjoyment in a positive manner.

There is a gradually growing number of studies on the behavior of old people and children as mobile gamers, but studies on female gamers are still rare. Schmitz, Klemke, Walhout, and Specht (2015) reported a mobile game application where children played an active role in the simulation of a dynamic process and provided principles and process for the interactive design of children's mobile games. Based on mobile games, they built an online environment encouraging the ubiquitous learning of children. Wang et al. (2017) noticed that loss of jobs, broken relationships, and failure in interpersonal relationships were reasons behind women's participation in mobile gaming. Merilampi et al. (2014) evaluated the effects of mobile games on older people with memory impairment. Findings indicate that mobile games can enhance the recreation and self-managed activity level of old people with memory impairment, and can potentially assist them in self-rehabilitation and extending independent living. With the growth of the older population, more mobile game apps will be designed for old people, helping them reduce cognitive decline. There are also studies reporting that mobile games can improve the quality of life and mental health of old people (Cota, Ishitani, \& Vieira, 2015), and help children with hearing impairment in overcoming hearing problems (Neves, Vanessa, \& Tania, 2017).

Values, consumer experience, lifestyle, safety, perceived risk, and subjective norms exert a more significant impact on users' intention to purchase mobile games. Online mobile game addiction significantly positively correlates with online mobile game loyalty and positively correlates with purchasing online mobile game applications. User online mobile game loyalty increases the intention to buy mobile games (Balakrishnan \& Griffiths, 2018). In addition, usability, perceived ease of use, and flow experience can promote the continuous use behavior of mobile game users. As a crucial scenario variable, diversion not only indirectly affects the continuous usage intention through the flow experience but also directly affects the continuous usage intention of the situation mobile game 
(Yanni Liu, Liu, Yuan, \& Archer, 2018). Students lack enthusiasm because they consider remembering English words and vocabulary are boring learning activities. The vocabulary learning system based on mobile games could effectively attract students' attention and interest, thereby producing better learning effects and providing positive feedback on learning motivation (Wu, 2018). Mobile games can effectively enhance users' creativity. Teenagers with a higher artistic sense of self-efficacy prefer playing situation mobile games than teenagers with lower self-efficacy; situation mobile games focusing on creative activities can effectively enhance participants' innovative sense of self-efficacy (Atwood-Blaine et al., 2019). Besides, mobile games can effectively encourage learners to participate in various educational activities and can increase the user's flow experience. In the process of playing mobile games, females get more flow experience than males (Bressler, Bodzin, \& Tutwiler, 2019). Of note, learning research based on mobile games has shown positive effects, and students' degree of empathy for characters in mobile games negatively correlates with their interest and knowledge of the game. In addition, the perception of the authenticity of content negatively correlated with the students' consumption rationality, which is conducive to enhancing students' ability to participate in teamwork (Huizenga, Admiraal, Dam, \& Voogt, 2019).

\section{Research on the Continuous Adoption Behavior of Mobile Game Users}

SNS games, as a new genre of games and one of the many functions of SNS, have become a concern of researchers who are interested in studying factors affecting the intention of gamers to play games. Shen (2013) measured how social and cultural factors affect SNS games. The study involved 11 interviewees and 321 questionnaire respondents. Findings indicate that social and cultural factors had significant effects on the appeal of SNS games. That's why many game developers have started to incorporate the social and cultural factors of different countries into the design of SNS games. P. S. Wei and H. P. Lu (2014) tried to find out the reasons behind gamers' affection for SNS games. Based on 237 valid questionnaires collected online and a structural equation, they discovered that network externalities had considerable effects on the willingness to play and satisfaction of gamers, and were associated with personal schedule flexibility. Avatar identification improves virtual community participation and social presence, these factors positively related to online gamer loyalty (Ching-I, 2017). Social influence is positively associated with purchase intentions for virtual goods, intention to continue playing is positively associated with purchase intentions (Hamari, 2015).

Hsiao and Chen (2016) studied factors driving the in-app purchase intention of mobile games. Baek and Touati (2017) investigated individual traits as predictors of game enjoyment by including learning style, intrinsic motivation, collaboration skills, and computer game attitude as key parts of a model that also included achievement. Results of correlation and regression analyses reveal that intrinsic motivation was the only variable to predict game enjoyment. Rauschnabel, Rossmann, and tom Dieck (2017) conducted a survey among 642 AR game players to explain drivers of their attitudinal and intentional reactions through a research framework built based on the gratification theory and flow theory. Results show that hedonic, emotional, and social benefits and social norms drove consumer reactions while physical risks (but not data privacy risks) hindered consumer reactions. However, the importance of these drivers differed depending on the form of user behavior. Chen and Leung (2016) conducted a survey among 409 Chinese mobile gamers to study their use of, especially addiction to mobile games. $7.3 \%$ of the respondents were considered addicts who were characterized as lonely, leisurely bored, and motivated by the mobile nature of the game. As expected, frequent players had a higher tendency to become addicts. In particular, loneliness and self-control were significant predictors of mobile social game addiction, whereas leisure boredom was linked to the intensity of game use. Researcher found that there are two types of motivations driving gamers, including ceremonial motivations such as passing time, escapism and hobby, hedonic motivations such as happiness, enjoyment and entertainment (Asta, Nikou, \& Gatautis, 2017; Hussain, Williams, \& Griffiths, 2015; Li, Liu, Xu, Heikkila, \& Heijden, 2015). 
Most mobile games are already available for free download. In the initial stage, mobile game developers primarily obtain revenue through product placement. However, developers using throughput agreements to charge become a trend (Rutz, Aravindakshan, \& Rubel, 2019). Learning letters is crucial in language learning, which is conducive to improving reading and writing skills. Nowadays, students prefer to learn through mobile games. Mobile games could improve teachers' ability to classify teaching content and students' ability to learn classified content, and decrease the interference of external environment on learning (Samur, 2019). The rapid advancement of mobile technology has made mobile games a leader in the global game market, and the mobile game market has grown in size and competition. Besides, the scale of the mobile game market has increased dramatically, with more intense competition. Furthermore, the market share of mobile games will monotonously decrease with time and continue increasing after the decline reaches the peak, and then begin to decline again, which presents a certain life cycle (Yi, Lee, \& Kim, 2019).

As more studies on mobile games are conducted, new theories will be constantly proposed, but gamers as objects of study will always be the core. Mobile gamer attrition, which is a type of gamer behavior, has also been studied. Most studies focus on building a customer attrition model, mainly in the communication industry, but overlook reasons causing mobile gamer attrition. Actually, reasons behind gamer attrition can explain gamers' willingness to play games to some extent. The paper creates a Model of Factors Affecting Women's Continuance intention for mobile games based on a technology acceptance model, and the validity of the created model has been verified.

Totally 21 papers including frequently used references and some latest studies discussing mobile games and the technology acceptance model have been included in the paper. Please see Table 1 for details.

\section{RESEARCH MODEL AND HYPOTHESES}

\section{Affective Factors and Perceived Enjoyment}

Economic motives and results were the focuses of information system adoption study, and cost was a key factor affecting people's information system adoption behavior. Hsiao and Chen (2016) argued that price greatly drove in-app purchase intention for mobile games. Kai-Shuan (2013) reported based on a statistical analysis that innovation and uniqueness were the main characterizations of popular games. The study contributed to human-computer interaction in cyberspace. Kim and Lee (2017) studied how switching costs and epistemic curiosity affect gamers' continuance intention for mobile games. Results show that the continuity cost and the sunk cost positively affected the retention intent, but there was no significant effect from learning cost. Focusing the gamer into as the male gamer, the learning cost was significant but negatively to the intent.

T. Huang, Bao, and Li (2017) found that satisfaction in enjoyment and social contact had significant positive effects on mobile gamers' willingness to buy, and vigor, players' dedication and absorption also significantly affected mobile gamers' willingness to buy. Xu et al. (2017) found that network density and the number of core gamers had positive effects on the price of massively multiplayer online role-playing games. Su, Chiang, James Lee, and Chang (2016) analyzed the effects of flow experience on the loyalty of mobile gamers. Results reveal that human-computer interaction, social interaction, challenge and skills all positively affected flow experience, and challenges had positive effects on the loyalty of mobile gamers. Personality traits are related to interdependence and network convergence, which fuel continuance intention of online gamers (Huang, Cheng, Wei-Fan, \& Ching-I, 2018). Thus, we propose the following hypotheses:

H1: Perceived challenges have significant positive effects on perceived enjoyment.

H2: Perceived novelty has significant positive effects on perceived enjoyment.

H3: Perceived cost has significant positive effects on perceived enjoyment. 
Table 1. A summary of previous studies about Mobile Game

\begin{tabular}{|c|c|c|c|}
\hline Author(s) & Key Variables & Study & Theoretical Basis \\
\hline Schmit et al. (2015) & Design & Design in mobile games for school children & Flow and Context \\
\hline Hsiao and Chen (2016) & Perceived value: Loyalty & $\begin{array}{l}\text { Factors of motivating game players to make } \\
\text { purchases }\end{array}$ & Value \\
\hline Su and Chen (2013) & Environment; design & $\begin{array}{l}\text { The mobile game-based insect learning system for } \\
\text { improving the learning achievements }\end{array}$ & TAM \\
\hline Su et al. (2016) & $\begin{array}{l}\text { Flow experience: Skill: } \\
\text { Human-computer: Interaction: } \\
\text { Challenge: Social interaction }\end{array}$ & $\begin{array}{l}\text { The effect of flow experience on player loyalty in } \\
\text { mobile game }\end{array}$ & Flow \\
\hline Cota et al. (2015) & Motivation; Age; Digital games & Mobile game design for the elderly & Flow \\
\hline Madeira et al. (2017) & User experience: Design & $\begin{array}{l}\text { The design and user experience of mobile game } \\
\text { for phonological disorders in children }\end{array}$ & Metaphon methodology \\
\hline Baek and Touati (2017) & Motivation: Skills: Attitude & $\begin{array}{l}\text { Study the influence of individual traits for } \\
\text { enjoyment in a mobile learning game }\end{array}$ & TAM \\
\hline Merikiv et al. (2017) & $\begin{array}{l}\text { Challenge: Variety: Novelty: } \\
\text { Design Playability }\end{array}$ & $\begin{array}{l}\text { The factors of making continued mobile gaming } \\
\text { enjoyable }\end{array}$ & TAM \\
\hline Rauschnabel et al. (2017) & $\begin{array}{l}\text { Hedonic: Emotional: Social } \\
\text { factor Social norm: Risk }\end{array}$ & $\begin{array}{l}\text { Investigate the mechanisms that explain the } \\
\text { popularity of mobile AR games }\end{array}$ & $\mathrm{U} \& \mathrm{G}$ \\
\hline Kim and Lee (2017) & $\begin{array}{l}\text { Epistemic curiosity: Gamer } \\
\text { attributes; Switching costs }\end{array}$ & $\begin{array}{l}\text { Gamer's attributes affecting continuous play } \\
\text { intention. }\end{array}$ & Flow \\
\hline Chen and Leung (2016) & $\begin{array}{l}\text { Mobility: Relaxation Sociability } \\
\text { Achievement: Entertainment }\end{array}$ & $\begin{array}{l}\text { Explore the relation of psychological factors to } \\
\text { mobile game use and addiction }\end{array}$ & $\mathrm{U} \& \mathrm{G}$ \\
\hline Zhu et al. (2011) & Service: Sound: Game view & Development of mobile games & UML \\
\hline Bai et al. (2012) & $\begin{array}{l}\text { Main class: Main program } \\
\text { Background class }\end{array}$ & Mobile game's design and implementation & TAM \\
\hline Lee et al. (2015) & $\begin{array}{l}\text { Mirroring service; Finger } \\
\text { movements }\end{array}$ & $\begin{array}{l}\text { Finger stroke time estimates for touchscreen-based } \\
\text { mobile gaming interaction }\end{array}$ & TAM \\
\hline Liu et al. (2016) & $\begin{array}{l}\text { Augmented reality: Interaction } \\
\text { Experience }\end{array}$ & $\begin{array}{l}\text { Analyzing students' language learning experience } \\
\text { in an augmented reality mobile game }\end{array}$ & U\&G \\
\hline Feijoo et al. (2012) & $\begin{array}{l}\text { Policy: Usable: Mobile Platform } \\
\text { Affordable: Content }\end{array}$ & $\begin{array}{l}\text { The industry challenges and policy implications of } \\
\text { Mobile gaming }\end{array}$ & TAM \\
\hline Okazaki et al. (2017) & $\begin{array}{l}\text { Inherent novelty social norms } \\
\text { seeking }\end{array}$ & $\begin{array}{l}\text { Factors influencing mobile gaming adoption } \\
\text { among the youth }\end{array}$ & TAM \\
\hline Shen et al. (2013) & $\begin{array}{l}\text { Practicable \& realizable; } \\
\text { Innovative \& unique }\end{array}$ & Explore the sociocultural appeal of SNS games & $\mathrm{U} \& \mathrm{G}$ \\
\hline Wei and Lu (2014) & $\begin{array}{l}\text { Network externality; } \\
\text { Gratifications }\end{array}$ & $\begin{array}{l}\text { Identify the factors that influence people to play } \\
\text { socially interactive mobile games }\end{array}$ & U\&G \\
\hline Xu et al. (2017) & $\begin{array}{l}\text { Network externality Density: } \\
\text { Closure }\end{array}$ & $\begin{array}{l}\text { Network externalities, density, and closure, would } \\
\text { exert impacts on the in-game currency price }\end{array}$ & Value \\
\hline Huang et al. (2017) & $\begin{array}{l}\text { Vigor: Flexibility Dedication: } \\
\text { Absorption Entertainment Self- } \\
\text { presentation }\end{array}$ & $\begin{array}{l}\text { Explore the purchase intention in mobile social } \\
\text { network games }\end{array}$ & $\mathrm{CE}$ and $\mathrm{U} \& \mathrm{G}$ \\
\hline
\end{tabular}

\section{Characteristics and Perceived Ease-of-Use of Mobile Games}

Mobile games can be played using smartphones, tablets and other portable computing devices. Compared to traditional computing devices, these devices feature easier access to the Internet, high mobility, and lighter weight, allowing gamers to play games anytime, anywhere. This explains the huge number of people playing games on smartphones. (Wei \& Lu, 2014) found that flexible play hours had positive effects on mobile gamer willingness to play games. Based on previous research which has proved the effects of system quality, information quality and service quality on gamers' willingness to play, (Wei \& Lu, 2014) reported that enjoyment and interaction were main factors 
deciding gamers' choosing mobile games, and the sense of satisfaction had positive effects on gamers' willingness to play mobile games. Jeon, Ahn, and Yu (2016) found that the user interface design of mobile games had positive effects on gamers' intention to play; and extensive information, active interaction, and content-related feedback had significant positive effects on the response of gamers. Mobile games are interactive products, which means their ease-of-use is a key factor affecting user interface design. Thus, the following hypotheses are proposed:

H4: Perceived mobility has significant positive effects on perceived ease-of-use.

H5: Perceived security has significant positive effects on perceived ease-of-use.

\section{Personal Perception and Willingness to Use}

Al-omoush and Shaqrah (2010) empirically studied the home network in Jordan based on the TAM and the theory of social consciousness, and found that perceived ease-of-use significantly affected gamers' willingness to play through perceived usefulness. Ismail, Razak, and Zakariah (2012) studied the e-learning system based on a TAM integrating such factors as information quality, service quality, system quality, perceived usefulness, and perceived ease-of-use. Results indicate that perceived usefulness significantly affected the students' willingness to continuously use in-apps. Byoungsoo (2010) performed an empirical study based on the ECM-ISC, finding that perceived usefulness, perceived playfulness, perceived cost, and satisfaction were main factors affecting mobile gamers' continuance in gaming. Enjoyment and usefulness are equally important determinants for using them (Hamari \& Keronen, 2017). Thus, we propose the following hypotheses:

H6: Perceived enjoyment has significant positive effects on continue to use.

H7: Perceived ease-of-use has significant positive effects on continue to use.

The paper builds a TAM in which factors affecting women's continuance intention for mobile games are divided into affective factors and game factors. The former was measured through challenge, novelty and cost, while the latter through mobility and privacy risks. Personal perceived factors were measured through perceived playfulness and perceived ease-of-use, and female gamers' willingness to play was measured through personal perceived factors. A hypothesis model shown in Figure 1 was created based on the above hypotheses.

This study primarily constructs and measures the variables, such as challenge, novelty, cost, perceived mobility, security, perceived ease of use, perceived enjoyment, and usage intention, when users play mobile games. All the measurement items of these variables are referenced to the existing mature scale and modified and improved in combination with the mobile game application scenario. The details are as follows: (1) Challenge. Based on Koufaris (2002), five measurement items, such as user thinking ability improvement, user ability expansion, and game skill improvement, were measured for female users during the usage of mobile games. (2) Novelty. Based on Huang (2003), five measurement items, such as innovation, imagination, and freshness of mobile games, were measured. (3) Cost. Referring to the study by Amberg et al. (2004) and Tang (2008), four measurement items, such as various expenses, time, and energy of users when playing mobile games, were measured. (4) Mobility. Based on Amberg et al. (2004) and Tang (2008), the degree to which a user can acquire a mobile game anytime and anywhere was measured, including three measurement items. (5) Privacy Risks. Based on Featherman et al. (2010), four measurement items, such as mobile games legality, personal privacy protection, and newcomers, were measured. (6) Perceived Enjoyment. Based on Koufaris (2002), the extent to which users feel happy, fun, and curious when using mobile games were measured, including four measurements items. (7) Perceived Ease of Use. Based on Davis (1989), the user's perception of the ease to use a mobile game was measured, including four measurements. 


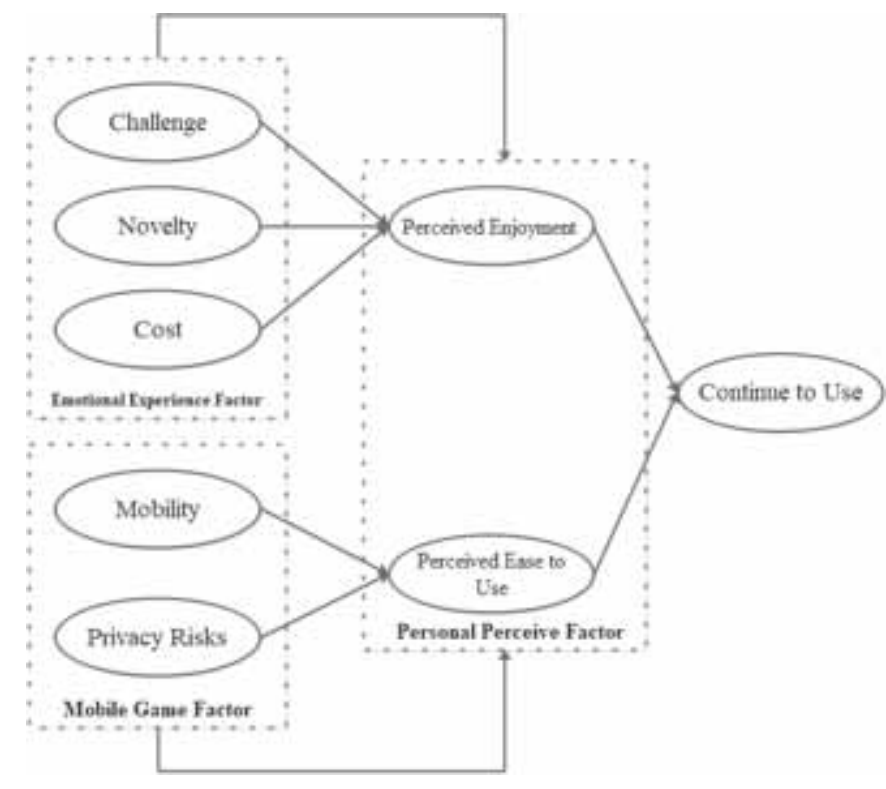

(8) Continue Using. Referring to Davis (1989), the possibility that consumers think they will use mobile games in the future was measured, including four measurements items.

\section{RESEARCH METHODOLOGY}

\section{Sampling and Data Collection}

A questionnaire survey has been carried out for the research. The questionnaire comprised three parts: basic information (e.g. the age, gender and income of the respondents), participation of respondents in mobile gaming (including frequency of playing mobile games and genres of games), and items regarding variables in the model built, a seven-point Likert scale was adopted. Due to limited research on female mobile gamers, perceived factors used herein were obtained by improving previous research. Through perfecting relevant scales, adjusting questions according to female mobile gamers' opinions, and feeding back questions evaluated by experts to the respondents, seven questions were finally determined to measure various factors. A pilot survey involving 20 female postgraduates at Wuhan University E-Commerce Lab was executed, and the structure and way of expression of the questionnaire were adjusted according to the results.

Through online survey platform and social commerce communities, totally 350 questionnaires have been collected, including 319 valid ones which accounted for $91 \%$ of the total. As shown in Table $2,73.98 \%$ of the respondents were under 35 , indicating that young women form the majority of female mobile gamers. $93.42 \%$ of the respondents had a bachelor's degree or above, indicating a high level of education. $80.56 \%$ of the respondents had serious careers at enterprises or schools. $80.25 \%$ of the respondents had an income above the average. Role-playing games, board games, music games, adventure games, casual games and puzzle games, which feature relaxing rhythm, were popular among female mobile gamers who were willing to spend more on in-app purchases. The results agree with the conclusions made by Flurry (2016). 
Table 2. Demographic information of the respondents

\begin{tabular}{|c|c|c|c|}
\hline Variable & Categories & Frequency & Percept \\
\hline \multirow{5}{*}{ Age } & Under 18 & 2 & 0.63 \\
\hline & $19-25$ & 52 & 16.3 \\
\hline & $26-35$ & 182 & 57.05 \\
\hline & $36-45$ & 57 & 17.87 \\
\hline & Over 45 & 26 & 8.15 \\
\hline \multirow{5}{*}{ Education } & Middle school or less & 1 & 0.31 \\
\hline & Senior school/Vocational school & 20 & 6.27 \\
\hline & Junior college/ Undergraduate & 269 & 84.33 \\
\hline & Master & 28 & 8.78 \\
\hline & Doctor & 1 & 0.31 \\
\hline \multirow{7}{*}{ Occupation } & Institution staff and civil servant & 113 & 35.42 \\
\hline & Enterprise technical staff and management & 122 & 38.24 \\
\hline & Teacher & 22 & 6.9 \\
\hline & Student & 22 & 6.9 \\
\hline & Housewife & 5 & 1.57 \\
\hline & Freelancer & 17 & 5.33 \\
\hline & Others & 18 & 5.64 \\
\hline \multirow{4}{*}{ Time of play the game } & Under half of time & 74 & 23.2 \\
\hline & Half of time to an hour & 134 & 42.01 \\
\hline & 1 hour-2 hours & 94 & 29.47 \\
\hline & Over 2 hours & 17 & 5.33 \\
\hline \multirow{8}{*}{ Kind of game people like } & Sports competition (Running racing, Skiing) & 64 & 20.06 \\
\hline & Action (Fruit ninja, Shadow of the blade) & 75 & 23.51 \\
\hline & Simulated business (Sims, Simulated city) & 77 & 24.14 \\
\hline & Leisure puzzle (Looking for your sister) & 106 & 33.23 \\
\hline & Adventure (Plant zombies) & 117 & 36.68 \\
\hline & Role play (Paladin, Dragon 8) & 134 & 42.01 \\
\hline & Music (Rhythm master, Big Musician) & 143 & 44.83 \\
\hline & Chess (Landlord, Chess) & 238 & 74.61 \\
\hline
\end{tabular}

\section{Tests of Reliability and Validity}

In this study, we used SPSS v.23 software to test the reliability and validity of the collected sample data. The coefficient of reliability of the questionnaire was 0.947 , and those of variables all exceeded 0.7 (see Table 3). The internal consistency of the questionnaire has been verified. Questions were designed by reference to mature scales and have been confirmed by experts, which ensured their content validity. The construct validity was obtained through KMO and Bartlett's Test. KMO was 0.923 and Bartlett P was less than 0.001. According to (J. Lu, Liu, \& Yu, 2008), when KMO is greater than 0.5 , it's ideal for factor analysis. Extracted main factors cumulatively explained $68.237 \%$ of the total variance. The validity of the questionnaire has been verified. 
Table 3. Results of confirmatory factor analysis

\begin{tabular}{|c|c|c|c|c|c|}
\hline Construct & Items & Factor Loading ${ }^{a}$ & Cronbach's $a$ & AVE & CR \\
\hline \multirow{5}{*}{ Challenge } & $\mathrm{CH} 1$ & 0.717 & 0.831 & 0.597 & 0.881 \\
\hline & $\mathrm{CH} 2$ & 0.764 & & & \\
\hline & $\mathrm{CH} 3$ & 0.817 & & & \\
\hline & $\mathrm{CH} 4$ & 0.780 & & & \\
\hline & $\mathrm{CH} 5$ & 0.783 & & & \\
\hline \multirow{5}{*}{ Novelty } & NO1 & 0.817 & 0.875 & 0.667 & 0.909 \\
\hline & $\mathrm{NO} 2$ & 0.757 & & & \\
\hline & $\mathrm{NO} 3$ & 0.829 & & & \\
\hline & NO4 & 0.841 & & & \\
\hline & NO5 & 0.835 & & & \\
\hline \multirow{4}{*}{ Cost } & $\mathrm{CO} 1$ & 0.791 & 0.811 & 0.639 & 0.876 \\
\hline & $\mathrm{CO} 2$ & 0.778 & & & \\
\hline & $\mathrm{CO} 3$ & 0.841 & & & \\
\hline & $\mathrm{CO} 4$ & 0.786 & & & \\
\hline \multirow{3}{*}{ Mobility } & MO1 & 0.908 & 0.837 & 0.756 & 0.903 \\
\hline & $\mathrm{MO} 2$ & 0.894 & & & \\
\hline & MO3 & 0.803 & & & \\
\hline \multirow{4}{*}{ Privacy Risks } & PR1 & 0.864 & 0.888 & 0.749 & 0.923 \\
\hline & PR2 & 0.875 & & & \\
\hline & PR3 & 0.890 & & & \\
\hline & PR4 & 0.831 & & & \\
\hline \multirow{4}{*}{$\begin{array}{l}\text { Perceived } \\
\text { Enjoyment }\end{array}$} & PE1 & 0.757 & 0.778 & 0.601 & 0.858 \\
\hline & PE2 & 0.759 & & & \\
\hline & PE3 & 0.819 & & & \\
\hline & PE4 & 0.764 & & & \\
\hline \multirow{4}{*}{$\begin{array}{l}\text { Perceived Ease } \\
\text { to Use }\end{array}$} & PEU1 & 0.866 & 0.843 & 0.681 & 0.895 \\
\hline & PEU2 & 0.806 & & & \\
\hline & PEU3 & 0.772 & & & \\
\hline & PEU4 & 0.854 & & & \\
\hline \multirow{4}{*}{ Continue to Use } & CTU1 & 0.861 & 0.901 & 0.772 & 0.931 \\
\hline & CTU2 & 0.896 & & & \\
\hline & CTU3 & 0.892 & & & \\
\hline & CTU4 & 0.864 & & & \\
\hline
\end{tabular}

Note: a All standardized factor loadings were significant at $p<0.001$

The observations of convergence validity include factor load, combination reliability (CR), and average extracted variance value (AVE). Notably, the three observation indexes have fulfilled the basic requirements of the test, suggesting that the survey scale has good convergence validity. 
Reliability reflects the stability and reliability of the observation scale, which is generally verified by Cronbach's $\alpha$ coefficient.

Table 3 shows that the factor loadings of observed variables all fall between 0.7 and 0.9 , greater than 0.50 and less than 0.95 , indicating that the basic fit indices of the scales are fairly ideal. The composite reliability values of latent variables are in the range of $0.800-0.930$, greater than the evaluation standard of 0.60 . The average variances extracted (AVE) of latent variables fall between 0.50 and 0.70 , greater than the evaluation standard of 0.50 . The reliability of the scales is high.

The validity test comprises content validity, convergence validity, and differential validity. Regarding the content validity, when selecting the initial scale, the relevant literature on the influencing factors of the continuous usage of mobile game users is organized and summarized, and the classical effective scale is combined to determine the measurement items of this study. In the formation process of the scale, the author conducted comprehensive research with the experts in related fields and performed frequent revisions of the questionnaire. Finally, the content and items of the questionnaire were determined, which ensured that the questionnaire had good content validity to the greatest extent.

The discriminant validity of latent variables indicates the low correlation or significant difference between observed variables and latent variables. In the paper, discriminant validity was tested based on the AVE of each latent variable, and the squared value of the correlation coefficient quantifying the statistical relationship between the latent variable and other latent variables. The discriminant validity values of latent variables are listed in Table 4.

Table 4. Results of discriminant validity analysis

\begin{tabular}{|l|l|l|l|l|l|l|l|l|}
\hline Construct & \multicolumn{1}{|c|}{ CH } & \multicolumn{1}{|c|}{ NO } & \multicolumn{1}{|c|}{ CO } & \multicolumn{1}{|c|}{ MO } & \multicolumn{1}{|c|}{ PR } & \multicolumn{1}{c|}{ PE } & PEU & CTU \\
\hline CH & 0.773 & & & & & & & \\
\hline NO & 0.487 & 0.817 & & & & & & \\
\hline CO & 0.001 & 0.011 & 0.799 & & & & & \\
\hline MO & 0.563 & 0.666 & 0.101 & 0.869 & & & & \\
\hline PR & 0.187 & 0.214 & 0.105 & 0.306 & 0.865 & & & \\
\hline PE & 0.584 & 0.620 & 0.060 & 0.578 & 0.189 & 0.775 & & \\
\hline PEU & 0.449 & 0.531 & 0.108 & 0.599 & 0.249 & 0.461 & 0.825 & \\
\hline CTU & 0.421 & 0.463 & 0.030 & 0.460 & 0.165 & 0.421 & 0.442 & 0.879 \\
\hline
\end{tabular}

Notes: CH: Challenge; NO: Novelty; CO: Cost; MO: Mobility; PR: Privacy Risks; PE: Perceived Enjoyment; PEU: Perceived Ease to Use; CTU: Continue to Use

Figures in diagonal are square root of the AVEs, and off-diagonal elements are corrections of constructs

The values on the diagonal in Table 4 are the square roots of the AVE of latent variables, and those off the diagonal are the squares of correlation coefficients reflecting the correlations among latent variables. To sum up, the survey scales are satisfactory in reliability and discriminant validity, which lay a solid foundation for further analyses.

\section{DATA ANALYSIS AND RESULTS}

Amos23 software was used to analyze collected data based on a structural equation model, and maximum likelihood estimation was adopted to verify the hypotheses raised in the theoretical model. 


\section{Parameter Estimation Reasonability Test}

Before estimating the overall fit of the model, it is necessary to test whether the model violates the estimation and verify the rationality of parameter estimation. In the model designed, the estimated values of standardized parameters all stayed below 0.95; the variances of measurement errors were between 0.123 and 8.007 (no negative variance); and the correlation coefficients reflecting the correlations among estimated covariances of latent variables all fell between 0.056 and 0.099 (less than 1). The reasonability of parameter estimation indicates that the covariance matrix or related matrix was positive define. The estimation results of the model show that there was no violation of the estimation, which allowed the overall fit test.

\section{Overall Fit Test of the Model}

In this paper, the overall fit evaluation indices of the model were divided into absolute fit indices, incremental fit indices and parsimonious fit index (Hair, Anderson, Tatham, \& Black, 1998). See Table 5 for overall model fit test statistic. The chi square $\left(x^{2}\right) /$ degree of freedom ratio (CMIN / DF) was 1.973 , less than 3 , indicating that the model was compatible with the actual sample data. However, since the chi-square and chi square/degree of freedom ratio are susceptible to the size of the sample, it is necessary to determine model fit by referring to other fit indices (Wheaton, 1987). Table 5 shows that the model has a RMSEA of 0.055 (less than 0.07 ), and a GFI value of 0.900 , a CFI of 0.98 , a TLI of 0.924 , and an IFI of 0.939 which are all greater than 0.9 , indicating that the overall model fit indices have reached the fit standard. Generally, the hypothetical model proposed herein was in good agreement with the actual observation data, and the structural equation model presented good external quality.

Table 5. Measures of the model fit

\begin{tabular}{|l|l|l|l|l|l|l|}
\hline \multicolumn{1}{|c|}{ Fit Index } & \multicolumn{1}{|c|}{$\boldsymbol{X}^{2} / \mathbf{d f}$} & \multicolumn{1}{|c|}{ RMSEA } & \multicolumn{1}{c|}{ GFI } & \multicolumn{1}{c|}{ CFI } & \multicolumn{1}{c|}{ TLI } & \multicolumn{1}{c|}{ IFI } \\
\hline Recommended value & $<3$ & $<0.07$ & $>0.9$ & $>0.9$ & $>0.9$ & $>0.9$ \\
\hline Model value & 1.973 & 0.055 & 0.900 & 0.938 & 0.924 & 0.939 \\
\hline
\end{tabular}

Source: According to Bentler and Bonett (1980)

\section{Research Hypothesis Test}

As shown in Table 6, the estimates obtained based on the structural equation model indicate that all hypotheses have been verified by the significance test, and are in agreement with theoretical analysis results and expectations. Test results indicate that perceived mobility had the greatest effects on perceived ease-of-use, while perceived risks had no obvious effects on perceived ease-of-use. Perceived cost had the least effects on perceived enjoyment, while perceived challenges had the greatest effects on perceived enjoyment.

In this study, we used Amos23. When the absolute value of CR was $>1.96$, and the P-value was $<0.05$, the correlation between the two potential variable paths was significant. The establishment of the hypothesis relationship between the latent variables in the theoretical model was confirmed by whether the path coefficients were significant or not.

Estimates obtained based on the structural equation model (see Figure 2) show that the path coefficient from perceived challenges to perceived enjoyment is 0.562 , greater that the significant value of 0.001 . Hypothesis H1 $(\beta=0.562, p<0.001)$ has been verified, indicating that stimulation and challenges raised by mobile games have positive effects on the perceived enjoyment of female gamers. The path coefficient from perceived novelty to perceived enjoyment is 0.540 , greater than the significant value of 0.540 . Hypothesis $\mathrm{H} 2(\beta=0.540, p<0.001)$ has been verified, indicating that 
Table 6. Summary of hypothesis tests

\begin{tabular}{|l|l|l|l|l|}
\hline \multicolumn{1}{|c|}{ Hypotheses } & \multicolumn{1}{c|}{ Standardized Coefficient } & \multicolumn{1}{c|}{ S.E. } & \multicolumn{1}{c|}{ C.R. } & \multicolumn{1}{c|}{ Supported } \\
\hline$H 1: \mathrm{CH} \rightarrow \mathrm{PE}$ & $0.562^{* * *}$ & 0.081 & 6.179 & Yes \\
\hline$H 2: \mathrm{NO} \rightarrow \mathrm{PE}$ & $0.540^{* * *}$ & 0.072 & 6.229 & Yes \\
\hline$H 3: \mathrm{CO} \rightarrow \mathrm{PE}$ & $0.127 * * *$ & 0.056 & 2.806 & Yes \\
\hline$H 4: \mathrm{MO} \rightarrow \mathrm{PEU}$ & $0.794 * *$ & 0.099 & 8.007 & Yes \\
\hline$H 5: \mathrm{PR} \rightarrow \mathrm{PEU}$ & 0.010 & 0.090 & 0.123 & No \\
\hline$H 6: \mathrm{PE} \rightarrow \mathrm{CTU}$ & $0.484 * *$ & 0.086 & 5.911 & Yes \\
\hline$H 7: \mathrm{PEOU} \rightarrow \mathrm{CTU}$ & $0.302^{* * *}$ & 0.070 & 3.949 & Yes \\
\hline
\end{tabular}

Note: ${ }^{* *} p<0.001$

Figure 2. Results of the proposed model

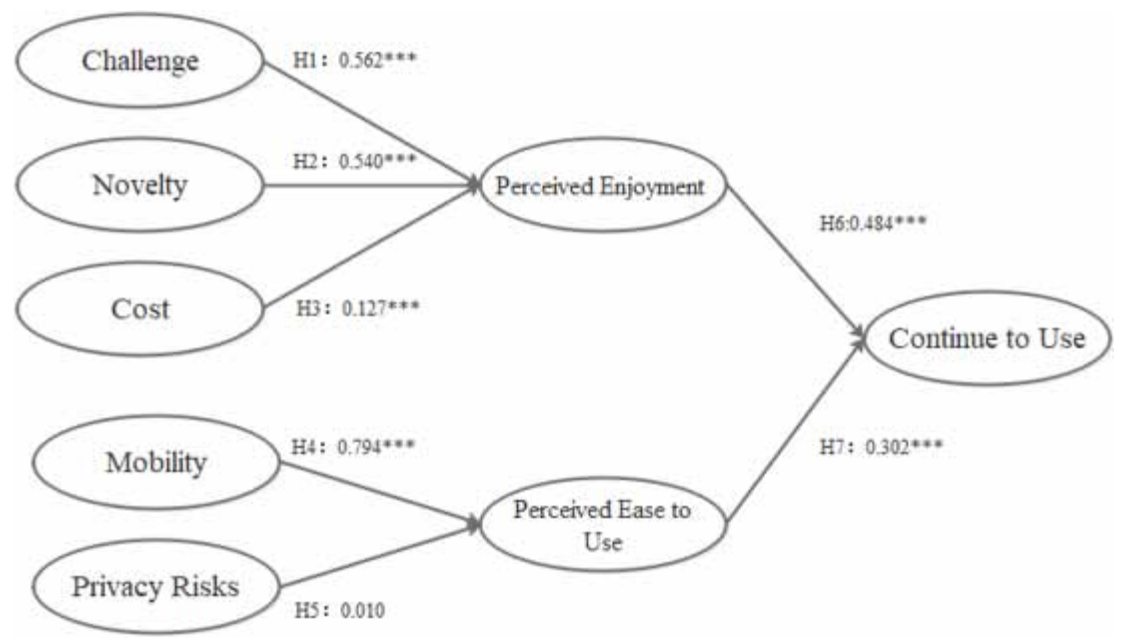

the novelty of mobile games had positive effects on the perceived enjoyment of female gamers. The path coefficient from price to perceived enjoyment is 0.127 , a little higher than the significant value of 0.001 . Hypothesis $\mathrm{H} 3(\beta=0.127, p<0.001)$ has been verified, indicating that the price of mobile games has minor positive effects on the perceived enjoyment of female gamers. This means female mobile gamers are not very sensitive to the cost of gaming. The path coefficient from the mobility of games to perceived mobility is 0.794 , greater than the significant value of 0.001 . Hypothesis $\mathrm{H} 4$ ( $\beta=0.794, p<0.001)$ has been verified, indicating that the ubiquitous of mobile games had positive effects on the perceived ease-of-use of female gamers. Well-performed networks and mobile terminals jointly create an environment where net female gamers can play mobile games anytime, anywhere. The path coefficient from privacy risks to perceived mobility is 0.010 , less than the significant value. Hypothesis 5 hasn't been verified, indicating that privacy risks have no positive effect on the perceived mobility of female mobile gamers. The path coefficient from perceived enjoyment to continuance intention for mobile games is 0.484 , greater than the significant value of 0.001 . Hypothesis H6 ( $\beta$ $=0.484, \mathrm{p}<0.001)$ has been verified, indicating that perceived enjoyment had positive effects on female gamers' continuance intention for mobile games. The path coefficient from perceived easeof-use to continuance intention for mobile games is 0.302 , greater than the significant value of 0.001 . 
Hypothesis H7 ( $\beta=0.302, \mathrm{p}<0.001$ ) has been verified, indicating that perceived ease-of-use had positive effects on female gamers' continuance intention for mobile games.

\section{CONCLUSION}

Based on a theoretical model and previous studies, the authors suggested new factors affecting female gamers' continuance intention for mobile games. Then, an empirical study was conducted based on the results of a questionnaire survey containing the above-suggested factors. Some research conclusions were made at last.

The paper studies factors affecting female gamers' continuance intention for mobile games based on a TAM. Perceived enjoyment and perceived ease-of-use were used as mediating variables. Findings show that perceived enjoyment and perceived ease-of-use had positive effects on female gamers' willingness to play mobile games (similar results were confirmed in studies conducted by (Bao, 2014; Juho Hamari \& Koivisto, 2015; Merikivi et al., 2017); the challenge, novelty and price (minor factor) of mobile games had positive effects on the perceived enjoyment of female gamers (similar results were confirmed in studies conducted by(Okazaki et al., 2015)); the ubiquitous of mobile games had positive effects on the perceived ease-of-use of female gamers (similar results were confirmed in studies conducted by(Baek \& Touati, 2017; Feijoo, Gómez-Barroso, Aguado, \& Ramos, 2012; Schmitz et al., 2015); and the privacy security of mobile games had no positive effect on the perceived mobility of female mobile gamers which means that privacy security was not a concern of female mobile gamers in the process of gaming.

Female mobile gamers have gradually developed mature gaming and payment habits. Fair games with shorter playtime and easier rules, being more stimulating than casual games and less stressful than traditional competitive games, are popular among female gamers. Female gamers tend to prefer social games featuring bright colors and a good gaming atmosphere. Given the characteristics of female mobile gamers, we believe that the traditional profit model depending on traffic acquisition is no longer suitable for the current female mobile games market-game operators need to increase the number of paid gamers and the amount of their payment through improving product quality, making innovations in design, integrating marketing resources, and precise data analysis. In the current context that social platforms have become a new battleground for operators and distributors (Rauschnabel et al., 2017), game developers should focus more on the integration of products with SNS, and recommended personalized games to female gamers.

\section{DISSCUSSION THE THEORETICAL AND MANAGERIAL IMPLICATIONS OF THE STUDY}

\section{Managerial Implications}

Findings of the study offer helpful guidance to mobile game developers, helping them develop products meeting the real needs of female gamers based on a better understanding of the behavior characteristics of female gamers, thus increasing market share. Challenges raised by mobile games have positive effects on the perceived enjoyment of female gamers. Therefore, developers should design more challenging missions, and create more impressive scenarios and story lines, increasing the sense of challenge for female gamers. The perceived enjoyment of female players is positively affected by the novelty of the game. To improve the novelty of games, developers should to frequently update roles and rewards, and develop new highlights through SNS for meeting the needs of female gamers on product novelty. The ubiquitous of mobile games have positive effects on the perceived ease-of-use of female gamers. In this respect, developers should rely on AR technology (Ma, 2016; Rauschnabel et al., 2017) to provide lightweight apps to female gamers, satisfying their needs of playing mobile games anytime, anywhere. For the design of mobile games, in addition to content, 
incorporate social systems may also be incorporated into game design, improving the interactivity among players, increasing customer loyalty.

\section{Theoretical Implications}

The paper adds new theories applied to the study of female mobile gamers in the process of studying the behavior characteristics of female mobile gamers in a more detailed manner by stressing the importance of factors such as challenges, novelty and mobility of mobile games in maintaining women's continuance intention for mobile games. In addition, the effects of proposed factors on women's continuance intention for mobile games have been proved, and factors affecting female gamers' perceived enjoyment and perceived ease-of-use have been verified. It's fair to say that the study can effectively enhance researchers' understanding of the information behavior of women. Through original application of the TAM in studying women's continuance intention for mobile games, the study has also proved that price is not a major factor affecting female gamers' willingness to play games. The paper provides a useful reference to researchers, helping them have a better understanding of the needs of female mobile gamers.

\section{LIMITATIONS AND FUTURE DIRECTIONS}

The limitations of this study are as follows. First, the survey used online questionnaires, and the number of collected questionnaires was limited. However, as the user groups of mobile games were relatively wide, this survey object was lacking in the universality of the sample. In addition, in the research content, this study combined the situation and satisfaction theory, and inevitably ignored the research focus and factors at other levels, resulting in a lack of extensive research perspective.

The future research plan is as follows. First, a comparative study would be conducted along with the behavioral characteristics of male mobile game users to examine the characteristics of different gender users. The future research plan is as follows. First, a comparative study would be conducted along with the behavioral characteristics of male mobile game users to examine the characteristics of different gender users.

Second, the behavioral characteristics of users of different ages would be further studied, with a focus on influencing factors of children and the elderly when using mobile games.

In future research, it would not only ensure the authenticity of the sample answer but also improve the number of samples. Meanwhile, the impact of regional and cultural factors on the continuous usage intention of mobile game users would be studied.

Technological attributes of mobile games and SNS have considerable effects on female mobile gamers' cognition, affection, and experiences which can actually be controlled by SNS and mobile game developers. However, this field is still not a big concern of researchers yet. In the future, further studies in this field may be conducted to explore how to positively affect female mobile gamers' cognition, affection, and experiences through increasing interactivity and telepresence in games using the power of technology.

\section{ACKNOWLEDGMENT}

This research was supported by the Hubei province university excellent young and middle-aged scientific and technological innovation team plan (T201730) in China. 


\section{REFERENCES}

Ahreum, L., Kibrum, S., Hokyoung, B. R., Jieun, K., \& Gyuhyun, K. (2015). Fingerstroke time estimates for touchscreen-based mobile gaming interaction. Human Movement Science, 44(5), 211-224. doi:10.1016/j. humov.2015.09.003 PMID:26401615

Al-omoush, K. S. \& Shaqrah, A. A. (2010). An empirical study of house-hold internet continuance adoption among Jordanian users. International journal of computer science and network security, 10(1), 32-44.

Alzahrani, A. I., Mahmud, I., Ramayah, T., Alfarraj, O., \& Alalwan, N. (2017). Extending the theory of planned behavior to explain online game playing among Malaysian undergraduate students. Telematics and Informatics, 34(4), 239-251. doi:10.1016/j.tele.2016.07.001

Asta, T., Nikou, S., \& Gatautis, R. (2017). Mobile application driven consumer engagement. Telematics and Informatics, 34(4), 145-156. doi:10.1016/j.tele.2017.01.006

Bae, J. H., \& Kim, A. H. (2014). Design and development of Unity3D game engine-based smart SNG. International Journal of Multimedia and Ubiquitous Engineering, 9(8), 261-266. doi:10.14257/ijmue.2014.9.8.23

Baek, Y., \& Touati, A. (2017). Exploring how individual traits influence enjoyment in a mobile learning game. Computers in Human Behavior, 69(12), 347-357. doi:10.1016/j.chb.2016.12.053

Balakrishnan, J., \& Griffiths, M. D. (2018). Loyalty towards online games, gaming addiction, and purchase intention towards online mobile in-game features. Computers in Human Behavior, 87(3), 238-246. doi:10.1016/j. chb.2018.06.002

Bao, C. (2014). A study on mobile game user's continuous usage intention: an integrated model of UTAUT. Nanjing: Context, Flow and Satisfaction.

Bressler, D. M., Bodzin, A. M., \& Tutwiler, M. S. (2019). Engaging middle school students in scientific practice with a collaborative mobile game. Journal of Computer Assisted Learning, 35(2), 197-207. doi:10.1111/ jcal.12321

Byoungsoo, K. (2010). An empirical investigation of mobile data service continuance: Incorporating the theory of planned behavior into the expectation-confirmation model. Expert Systems with Applications, 37(10), 7033-7039. doi:10.1016/j.eswa.2010.03.015

Chang, I. C., Liu, C. C., \& Chen, K. (2014). The effect of hedonic/utilitarian expectations and social influence on continuance intention to play online games. Internet Research, 24(1), 21-45. doi:10.1108/IntR-02-2012-0025

Chen, C., \& Leung, L. (2016). Are you addicted to Candy Crush Saga? An exploratory study linking psychological factors to mobile social game addiction. Telematics and Informatics, 33(4), 1155-1166. doi:10.1016/j. tele.2015.11.005

Ching-I, T. (2017). Impact of avatar identification on online gamer loyalty: Perspectives of social identity and social capital theories. International Journal of Information Management, 37(6), 601-610. doi:10.1016/j. ijinfomgt.2017.06.006

Chuang-Chun, L. (2016). Model of online game addiction: The role of computer-mediated communication motives. Telematics and Informatics, 33(4), 904-915. doi:10.1016/j.tele.2016.02.002

Cota, T. T., Ishitani, L., \& Vieira, N. Jr. (2015). Mobile game design for the elderly: A study with focus on the motivation to play. Computers in Human Behavior, 51(5), 96-105. doi:10.1016/j.chb.2015.04.026

De Kervenoael, R., Palmer, M., \& Hallsworth, A. (2013). From the outside in: Consumer anti-choice and policy implications in the mobile gaming market. Telecommunications Policy, 37(6-7), 439-449. doi:10.1016/j. telpol.2012.06.008

Feijoo, C., Gómez-Barroso, J.-L., Aguado, J.-M., \& Ramos, S. (2012). Mobile gaming: Industry challenges and policy implications. Telecommunications Policy, 36(3), 212-221. doi:10.1016/j.telpol.2011.12.004

Hair, J. F., Anderson, R. E., Tatham, R. L., \& Black, W. C. (1998). Multivariate Data Analysis (Vol. 5th edn). New Jersey: Prentice Hall 
Hamari, J. (2015). Why do people buy virtual goods? Attitude toward virtual good purchases versus game enjoyment. International Journal of Information Management, 35(3), 299-308. doi:10.1016/j. ijinfomgt.2015.01.007

Hamari, J., \& Keronen, L. (2017). Why do people play games? A Meta-Analysis. International Journal of Information Management, 37(3), 125-141. doi:10.1016/j.jinfomgt.2017.01.006

Hamari, J., \& Koivisto, J. (2015). Why do people use gamification services? International Journal of Information Management, 35(4), 419-431. doi:10.1016/j.jinfomgt.2015.04.006

Hamari, J., \& Sjoblom, M. (2017). What is eSports and why do people watch it. Internet Research, 27(2), 211-232. doi:10.1108/IntR-04-2016-0085

Hsiao, K.-L., \& Chen, C.-C. (2016). What drives in-app purchase intention for mobile games? An examination of perceived values and loyalty. Electronic Commerce Research and Applications, 16(5), 18-29. doi:10.1016/j. elerap.2016.01.001

Huang, H.-C., Cheng, T. C. E., Wei-Fan, H., \& Ching-I, T. (2018). Impact of online gamers' personality traits on interdependence, network convergence, and continuance intention: Perspective of social exchange theory. International Journal of Information Management, 38(1), 232-242. doi:10.1016/j.ijinfomgt.2017.08.009

Huang, T., Bao, Z., \& Li, Y. (2017). Why do players purchase in mobile social network games? An examination of customer engagement and of uses and gratifications theory. Program, 51(3), 259-277. doi:10.1108/PROG12-2016-0078

Huizenga, J., Admiraal, W., Dam, G., \& Voogt, J. (2019). Mobile game-based learning in secondary education: Students' immersion, game activities, team performance and learning outcomes. Computers in Human Behavior, 99, 137-143. doi:10.1016/j.chb.2019.05.020

Hussain, Z., Williams, G. A., \& Griffiths, M. D. (2015). An exploratory study of the association between online gaming addiction and enjoyment motivations for playing massively multiplayer online role-playing games. Computer in Human Behavior, 50(1), 221-230.

Iresearch. (2017). Chian Mobile Game Industry Research Report. Retrieved from http://report.iresearch.cn/ report.pdf.aspx?id=3043

Ismail, N. Z., Razak, M. R., \& Zakariah, Z. (2012). E-learning continuance intention among higher learning institution students' in Malaysia. Procedia: Social and Behavioral Sciences, 67(67), 409-415.

Jeon, H., Ahn, H. J., \& Yu, G. J. (2016). What makes people react to the posts on the brand pages of mobile social network games? Online Information Review, 40(3), 435-448. doi:10.1108/OIR-07-2015-0236

Kai-Shuan, S. (2013). Measuring the sociocultural appeal of SNS games in Taiwan. Internet Research, 23(3), 372-392. doi:10.1108/10662241311331781

Kim, Y.-B., \& Lee, S.-H. (2017). Mobile gamer's epistemic curiosity affecting continuous play intention. Focused on players' switching costs and epistemic curiosity. Computers in Human Behavior, 77(8), 32-46. doi:10.1016/j.chb.2017.08.023

Lee, C. C., Hsu, S. H., \& Chang, J. W. (2013). Factors influence sociability in educational MMORPGs a fuzzy AHP approach. Internet Research, 23(3), 298-315. doi:10.1108/10662241311331745

Li, H., Liu, Y., Xu, X., Heikkila, J., \& Heijden, H. V. D. (2015). Modeling hedonic is continuance through the uses and gratifications theory: an empirical study in online games. computer in Human Behavior, 48(1), 261-272.

Lin, C. Y., Hung, W. H., Fang, K., \& Tu, C. C. (2015). Understanding player's achievement values from MMORPGs: An exploratory study. Internet Research, 25(5), 829-851. doi:10.1108/IntR-12-2013-0268

Liu, Y., Daniel, H., \& Dongping, Z. (2016). Analyzing students language learning experience in an augmented reality mobile game: an exploration of an emergent learning environment. Procedia: Social and Behavioral Sciences, 228(2), 369-374. doi:10.1016/j.sbspro.2016.07.055

Liu, Y., Liu, D., Yuan, Y., \& Archer, N. (2018). Examining situational continuous mobile game play behavior from the perspectives of diversion and flow experience. Information Technology \& People, 31(4), 948-965. doi:10.1108/ITP-02-2016-0042 
Lu, H. P., \& Wang, S. M. (2008). The role of internet addiction in online game loyalty: An exploratory study. Internet Research, 18(5), 499-519. doi:10.1108/10662240810912756

Lu, J., Liu, C., \& Yu, C. S. (2008). Determinants of accepting wireless mobile data services in china. Information \& management, 45(1), 52-64.

Ma, Q. (2016). Interactive model analysis of mobile game virtual community-A case study of Fantasy Westward Journey. Guangdong.

Merikivi, J., Tuunainen, V., \& Nguyen, D. (2017). What makes continued mobile gaming enjoyable? Computers in Human Behavior, 68(6), 411-421. doi:10.1016/j.chb.2016.11.070

Merilampi, S., Peter, C., Professor Gail Mount, D., Sirkka, A., Leino, M., Koivisto, A., \& Finn, E. (2014). Cognitive mobile games for memory impaired older adults. Journal of Assistive Technologies, 8(4), 207-223. doi:10.1108/JAT-12-2013-0033

Neves, M. R., Vanessa, M., \& Tania, F. (2017). Phonological disorders in children? design and user experience evaluation of a mobile serious game approach. Paper presented at the ICTH 2017.

Okazaki, S., \& Radoslav, S., \& IIdefonso, G. (2015). Golbal youth and mobile games: Appling the Extended technology acceptance model in the USA, Japan, Spain, and the Czech Republic. Cross-Cultural Buyer Behavior, $18(2), 253-270$.

Pan, J. W., \& Fu, W. (2013). Love internet, love online content: Predicting internet affinity with information gratification and social gratifications. Internet Research, 23(4), 396-413.

Park, E., Baek, S., Ohm, J., \& Chang, H. J. (2014). Determinants of player acceptance of mobile social network games: An application of extended technology acceptance model. Telematics and Informatics, 31(1), 3-15. doi:10.1016/j.tele.2013.07.001

Rauschnabel, P. A., Rossmann, A., \& tom Dieck, M. C. (2017). An adoption framework for mobile augmented reality games: The case of Pokémon Go. Computers in Human Behavior, 76(7), 276-286. doi:10.1016/j. chb.2017.07.030

Rutz, O., Aravindakshan, A., \& Rubel, O. (2019). Measuring and forecasting mobile game app engagement. International Journal of Research in Marketing, 36(2), 185-199. doi:10.1016/j.jiresmar.2019.01.002

Schmitz, B., Klemke, R., Walhout, J., \& Specht, M. (2015). Attuning a mobile simulation game for school children using a design-based research approach. Computers \& Education, 81(6), 35-48. doi:10.1016/j. compedu.2014.09.001

Shen, K. S. (2013). Measuring the sociocultural appeal of SNS games in Taiwan. Internet Research, 23(3), 372-392. doi:10.1108/10662241311331781

Su, Y.-S., Chiang, W.-L., James Lee, C.-T., \& Chang, H.-C. (2016). The effect of flow experience on player loyalty in mobile game application. Computers in Human Behavior, 63(4), 240-248. doi:10.1016/j.chb.2016.05.049

Vashisht, D., \& Sreejesh, S. (2017). Effect of nature of the game on ad-persuasion in online gaming context: moderating roles of game-product congruence and consumer's need for cognition. Internet Research, 27(1), 52-73. doi:10.1108/IntR-10-2014-0271

Wang, Y.-S., Lee, W.-L., \& Hsu, T.-H. (2017). Using netnography for the study of role playing in female online games: Interpretation of situational context model. Internet Research, 27(4), 905-923. doi:10.1108/IntR-042016-0111

Wei, P.-S., \& Lu, H.-P. (2014). Why do people play mobile social games? An examination of network externalities and of uses and gratifications. Internet Research, 24(3), 313-331. doi:10.1108/IntR-04-2013-0082

Wei, P. S., \& Lu, H. P. (2014). Why do people play mobile social games? An examination of network externalities and of uses and gratifications. Internet Research, 24(3), 313-331. doi:10.1108/IntR-04-2013-0082

Wheaton, B. (1987). Assessment of Fit Overidentified Models with Variables. Sociological Methods \& Research, 16(1), 118-154. doi:10.1177/0049124187016001005 
Wu, T.-T. (2018). Improving the effectiveness of English vocabulary review by integrating ARCS with mobile game-based learning. Journal of Computer Assisted Learning, 34(3), 315-323. doi:10.1111/jcal.12244

Xu, X., Yang, X., Lu, J., Lan, J., Peng, T.-Q., Wu, Y., \& Chen, W. (2017). Examining the effects of network externalities, density, and closure on in-game currency price in online games. Internet Research, 27(4), 924-941. doi:10.1108/IntR-07-2016-0201

Yang, L. S., \& Sik, S. Y. (2014). Design and implementation of the WIPI-to-Android automatic mobile game converter for the contents compatibility in the heterogeneous mobile OS. Journal of Systems Architecture, 60(5), 693-701. doi:10.1016/j.sysarc.2013.10.010

Yi, J., Lee, Y., \& Kim, S.-H. (2019). Determinants of growth and decline in mobile game diffusion. Journal of Business Research, 99(5), 363-372. doi:10.1016/j.jbusres.2017.09.045

Pinghao $\mathrm{Ye}$ is an associate professor at the School of Information Engineering, Wuhan Business University, China. He obtained a BS (Management Science and Engineering) from the Wuhan University of Technology, and a PhD (Management Science and Engineering) from Wuhan University. His research interests involve data mining and information processing, digital library, citation analysis, bibliometric, knowledge management and business intelligence, social networks analysis and visualization.

Liqiong Liu is an associate professor at the School of Business Administration, Wuhan Business University, China. She obtained PhD (Electronic Commerce) from Wuhan University. Her research interests include electronic commerce, social network, business information analysis. Her publications have appeared in Journal of Modern Information, The Electronic Library, International Journal of Emerging Technologies in Learning, and in the proceedings of some international conferences.

Linxia Gao is an undergraduate student at school of information engineering, her research interest includes electronic commerce and social commerce.

Quanjun Mei is an undergraduate student at school of information engineering, her research interest includes electronic commerce and social commerce. 